\title{
Investigation of the Effect of Workpiece Resolution on Milling Simulation Accuracy in Production Module 3D CAE Software
}

\author{
Piotr LÖSCHNER, Krzysztof JAROSZ, Piotr NIESŁONY
}

\begin{abstract}
The aim of this work was to present the effect of workpiece resolution on simulation accuracy in Production Module 3D CAE software. The concept of resolution and working principle of CAD model conversion into proprietary ${ }^{*}$.TWSM format was explained. Next, the effects of model resolution on simulation results were presented, using an example of a face milling operation. Four different workpiece model resolutions were used, including the resolution value recommended by the software developer. Comparison of simulation results for different workpiece resolutions was conducted, obtained results were analysed, with particular focus on the effect of workpiece resolution on simulated cutting force values. The authors have found a substantial link between workpiece resolution, material removal rate and simulation accuracy.
\end{abstract}

Keywords: CAD model; cutting force; Production Module 3D; simulation accuracy; workpiece model resolution

\section{INTRODUCTION}

Presently, utilization of specialized software for design, evaluation and optimization of manufacturing processes has grown significantly due to rapid computerization and automation of machining industry. Introduction of modern construction materials and tighter tolerances demands the use of more robust and precise cutters and machine tools. Reliable and optimal machining strongly depends on many factors, such as the type and condition of the cutting machine $[1,2]$, tool geometry [3$5]$ or process parameters $[6,7]$. Usually industry expects more accurate machining methods $[8,9]$ to face the challenges related to technological progress. Eventual errors and mishaps in $\mathrm{CNC}$ tool path programming design can lead to poor tool life, poor surface quality, unnecessarily long machining time or in the worst case scenario, collisions between the workpiece and tool, holder or other machine tool elements. This in turn leads to excessive increase in production costs, downtime and spending on machine maintenance/repair. Several CAE software packages have been developed with the aim of $\mathrm{CNC}$ toolpath verification and optimization. One of those programs is Production Module 3D developed by Third Wave Systems. It was designed especially for toolpath verification, optimization and simulation, providing the end used with plethora of information about cutting forces, feeds, cutting speeds, spindle loads amongst others. Production Module 3D (PM3D) features and functionality, along with optimization examples, have been described in articles [10-12]. Besides requiring certain input data to simulate the machining process, it is vital to supply PM3D with a workpiece model and properly determine workpiece resolution.

The aim of this work is to explain the concept of workpiece model resolution in PM3D software, the working principle of conversion of $3 \mathrm{D}$ CAD model into a proprietary *.TWSM format, and most importantly the effect of workpiece resolution on simulation accuracy.

\section{WORKPIECE MODEL RESOLUTION}

Machining simulations in PM3D software require input data in the form of $\mathrm{CNC}$ toolpaths, $\mathrm{CAD}$ workpiece and tool models and material model. An appropriate material model can be chosen from a vast array of materials available in PM3D library, or defined by the end used on the basis of previously conducted oblique turning tests [6]. A CNC toolpath can be generated in CAM software of user's choice or written by a CNC programmer. CAD workpiece model can be imported straight from CAD software in which it was designed. Production Module 3D currently supports files in *.STP, *.STEP and *.STL formats.

In the process of importing a 3D workpiece model, PM3D converts it into a proprietary *.TWSM (Third Wave Solid Model) format, dividing the model into a specified number of finite elements for future computational purposes. Workpiece resolution $r$ is defined as a number of elements constituting the model after its conversion from a CAD file $[13,14]$. The concept of workpiece resolution is explained in fig. 1 with the use of a cubic block.
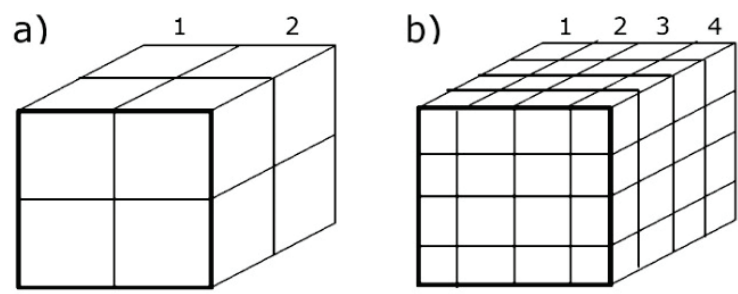

Figure 1 Workpiece resolution in PM3D software; a) a cubic block with resolution res=2. b) same block with resolution res=4 [14]

It can be expected that simulation accuracy will improve with resolution increase, especially for more complicated workpiece geometries. However, an excessive increase in workpiece resolution can result in prolonged computation times and slower operation of $3 \mathrm{D}$ machining visualization module [13].

\section{DETERMINING WORKPIECE RESOLUTION IN PM3D}

To secure a good coherence of simulated parameters with those occurring in a real-life machining process, an agreement in volume of simulated and actually removed material is essential. The effect on incorrect workpiece resolution on material removal is shown in Fig. 2. 
a)

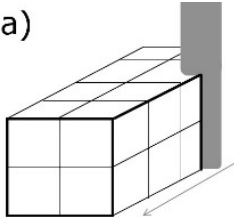

b)

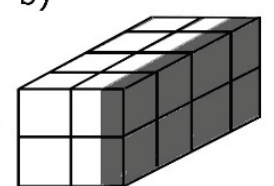

c)

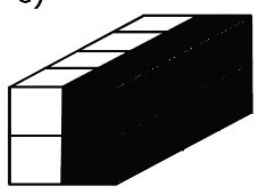

Figure 2 The effect on incorrect resolution on material removal simulation results; a) a simple end milling operation, b) actual material removed, c) simulated material removed [7]

As can be seen in Fig. 2, too low resolution results in overestimation of simulated removed material volume in relation to a real-life example. This is particularly detrimental when the width of a single row of finite elements is far greater than the width of a single machining pass. This situation results in further errors in simulation, as shown in Fig. 3.

a)

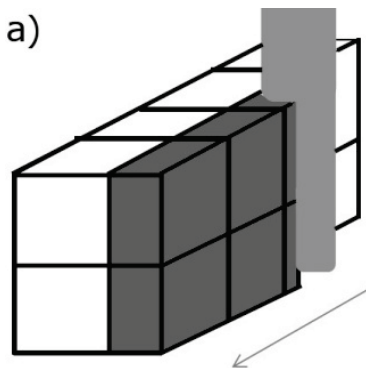

Figure 3 The effect of incorrect workpiece resolution on material removed in a second machining pass; a) actual material removed in second pass, b) simulated material removed [7]

From looking at Fig. 2 b), it is evident that Production Module 3D removes no material in second pass. Therefore, a significant distortion of simulated machining force can be expected when comparing simulation results with experimental data. A graph in Fig. 4 provides a schematic explanation.

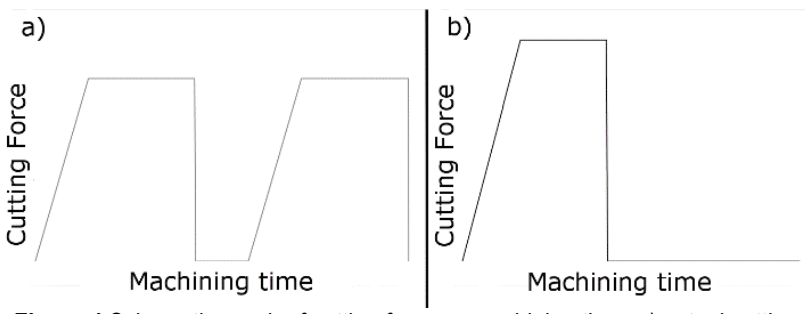

Figure 4 Schematic graph of cutting force vs machining time; a) actual cutting force value, $b$ ) incorrect simulation results due to incorrect workpiece resolution [14]

As seen in Fig.4, an assumption of incorrect workpiece resolution results in significant errors in cutting force values for simulation (b) in comparison to experiment (a). Simulated cutting force value is significantly higher for the first machining pass, while for the second pass there is no cutting force present, as there is no material left to be removed.

To prevent the occurrence of errors and inconsistencies seen in Figs. 2, 3, 4, an equation for correct workpiece resolution $r$ was proposed [14]:

res $=\frac{\mathrm{d}_{\max }}{d_{\min }} \cdot 2$ where: res - workpiece resolution; $d_{\max }$ - largest part feature; $d_{\min }$ - smallest part feature (for example, smallest edge fillet/chamfer)

A largest part feature should be understood as a largest part dimension in case of simple workpiece geometries. A smallest part feature for simple geometries should be equal to $D_{c a p}$ (cutting diameter at used cutting depth $a_{p}$ ) or depth of cut $a_{p}$ if it is lesser than the cutting diameter of used tool. If workpiece resolution is determined correctly, no significant difference between experimental data and simulation results should occur. This is schematically shown in Fig. 5.

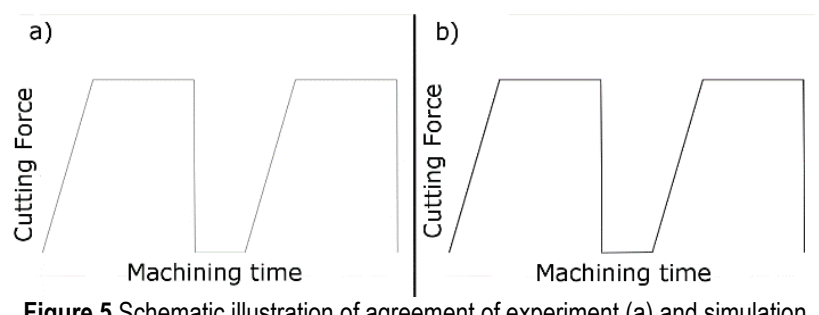

Figure 5 Schematic illustration of agreement of experiment (a) and simulation (b) results achievable for correctly determined workpiece resolution [14]

It is very important to note that to achieve a good agreement of simulation and experiment results, several other key factors have to be correctly determined. A correct material model has to be chosen or defined by the end user, along with proper Virtual Machine setup in PM3D (Machine Settings tab). The adherence of simulation to a real-life process (exact replication of workpiece geometry, cutter parameters, process parameters such as feeds, speeds, CNC toolpath) is also vital to obtaining satisfactory results. A properly prepared simulation in Production Module results in a maximum error of $15 \%$ in cutting force values when compared to experimental data.

\section{WORKPIECE RESOLUTION TESTING}

Several simulations of a face milling process were performed in Production Module 3D to test the effect of different workpiece resolutions on simulation results and computation times.

The input technological process was designed with the aid of Mastercam X4 CAM software. Process parameters are described in table 1.

The generated $\mathrm{CNC}$ toolpath was imported into Production Module 3D, along with workpiece and cutting tool 3D CAD models in *.STP format. The imported process is presented in Fig. 6

Table 1 Process parameters

\begin{tabular}{|l} 
Table 1 Process parameters \\
\begin{tabular}{|l|c|}
\hline \multicolumn{1}{|c|}{ Workpiece } & $50 \times 50 \times 20 \mathrm{~mm}$ cubic block \\
\hline Workpiece material & C45 Steel \\
\hline Cutter & Kennametal F3BS Solid end roughing mill \\
\hline Cutter material & KCPM15 grade carbide \\
\hline Number of flutes & 3 \\
\hline Corner radius $r_{c}, \mathrm{~mm}$ & 0.45 \\
\hline Cutter diameter $D c, \mathrm{~mm}$ & 20 \\
\hline Surface speed $v_{c}, \mathrm{~m} / \mathrm{min}$ & 150 \\
\hline Feed per tooth $f_{p t}, \mathrm{~mm}$ & 0,08 \\
\hline
\end{tabular}
\end{tabular}

A Dell Precision series workstation equipped with an Intel Xeon E-1245 v3 $8 \times 3,4 \mathrm{GHz} \mathrm{CPU}$ and $8192 \mathrm{MB}$ DDR3 RAM Memory was used for the simulation. 


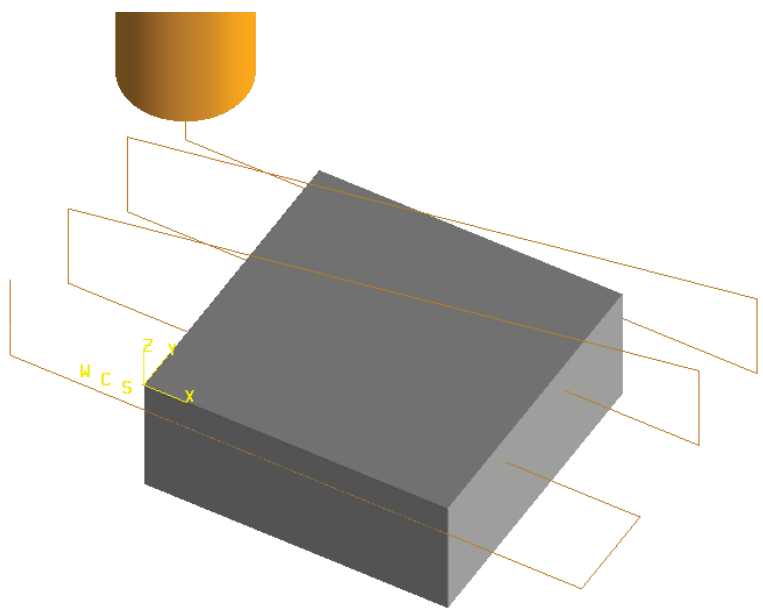

Figure 6 Technological process setup in PM3D

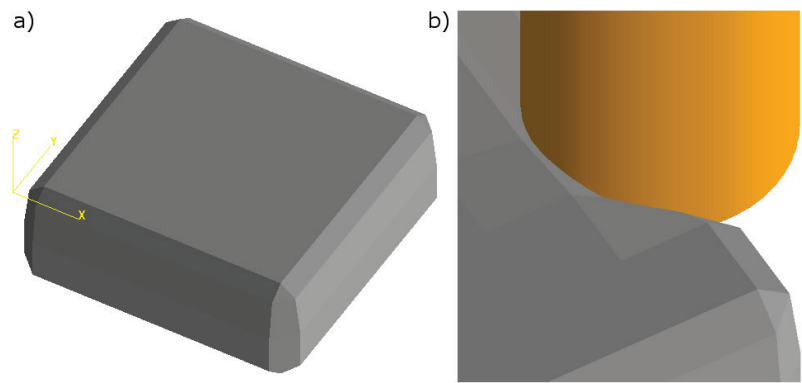

Figure 7 Workpiece render a) and cutting process simulation b) for workpiece resolution $r e s 1=10$

Four different workpiece resolutions were assumed, as shown in Figs. $7 \div 10$. Resolution res 2 was calculated according to Eq. (1):

$r=\frac{d_{\max }}{d_{\min }} \cdot 2=\frac{50}{5} \cdot 2=20$
Width of the block ( $w=50 \mathrm{~mm})$ was assumed as the largest part feature $d_{\max }$, whereas cutting depth $\left(a_{p}=5 \mathrm{~mm}\right)$ was assumed as the smallest part feature $d_{\text {min }}$.

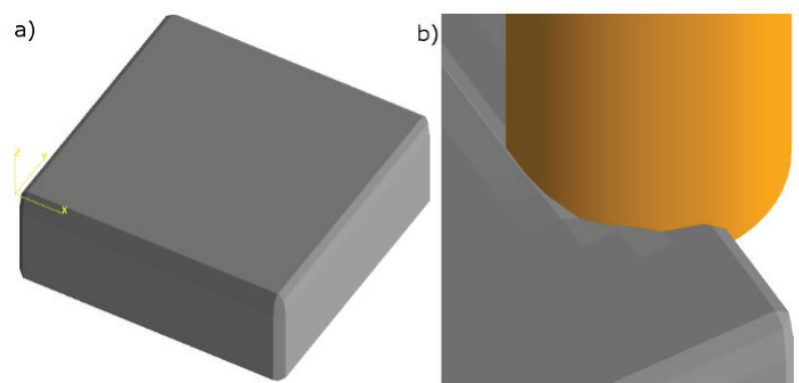

Figure 8 Workpiece render a) and cutting process simulation b) for workpiece resolution res $2=20$

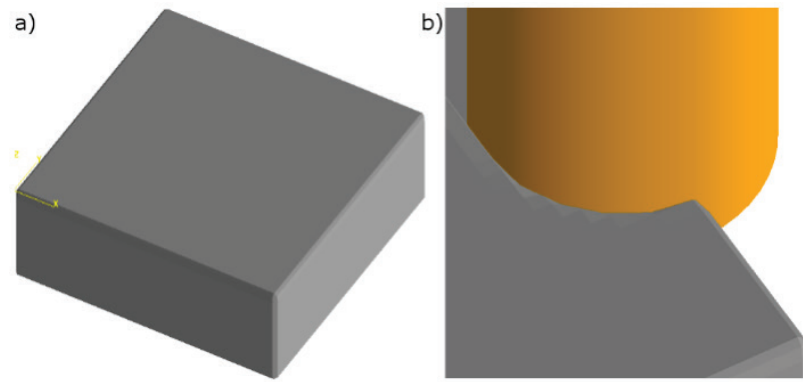

Figure 9 Workpiece render a) and cutting process simulation b) for workpiece resolution res $3=40$

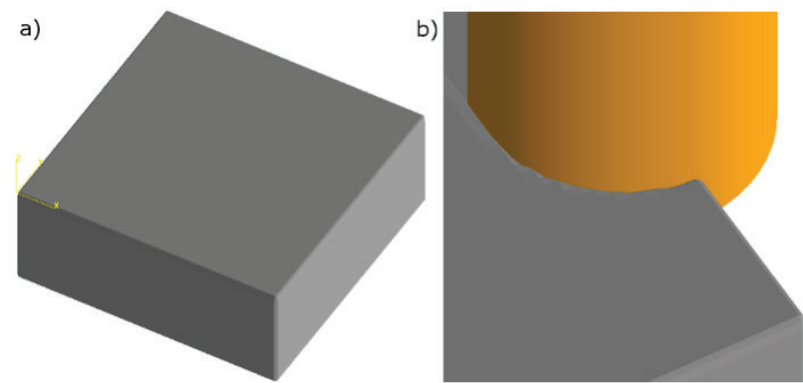

Figure 10 Workpiece render a) and cutting process simulation b) for workpiece resolution res $4=60$

Tangential cutting force vs Machining time

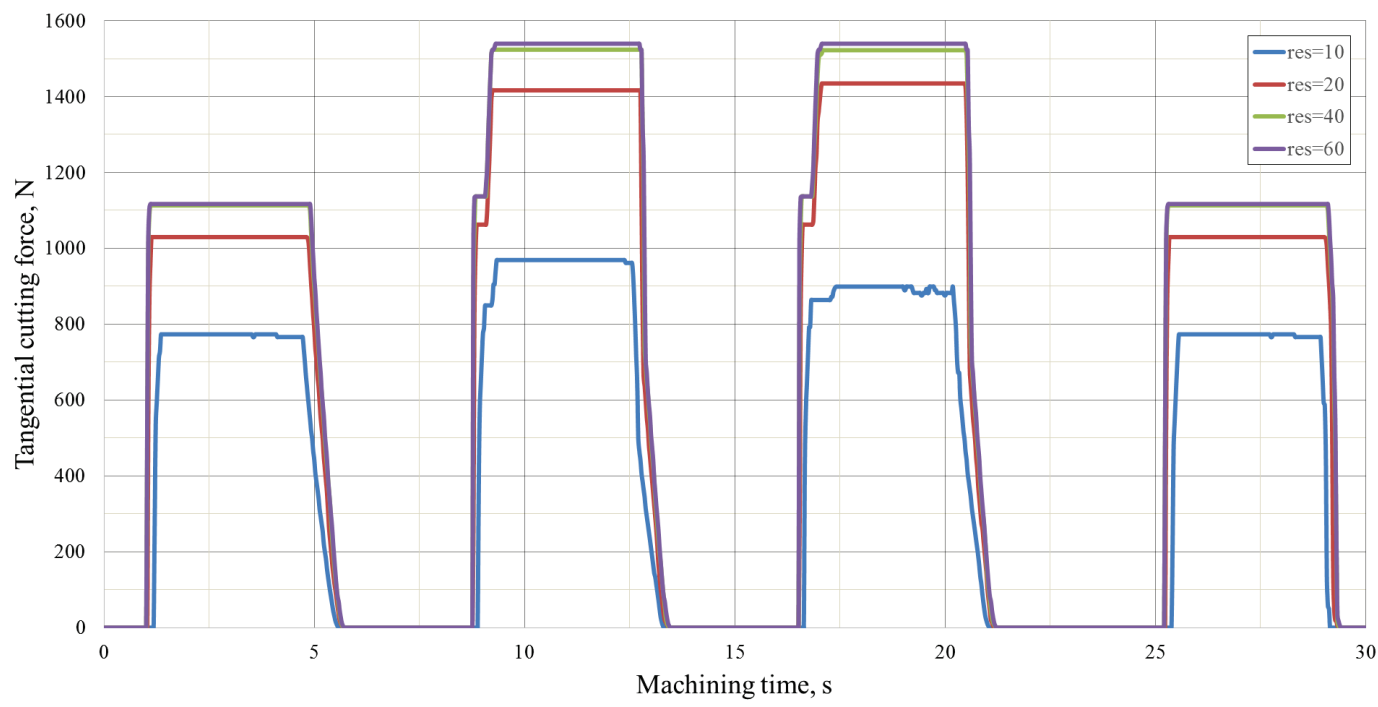

Figure 11 Tangential cutting force values for assumed workpiece resolutions

It can be clearly seen that different resolution values severely affect workpiece model discretization. There is a substantial difference in size of finite elements that are removed during cutting simulation with different 
resolutions. Therefore, variations are cutting force values and material removal rates can be expected between different resolutions. Tangential force and material removal rates for assumed resolutions are presented in Figs. 11, 12.

As can be seen in Fig. 11, the biggest differences occur between resolutions of $\operatorname{res} 1=10$ and $\operatorname{res} 2=20$. Tangential force value for res 1 is underestimated by $33 \div 71 \%$ in comparison to values obtained for three other workpiece resolutions. With the increase in force value, the difference between used workpiece resolutions becomes more evident. Only insignificant differences ( $2 \%$ maximum) can be seen between force values when using resolutions res 3 and res4. This leads to a conclusion that increasing workpiece resolution above a certain value does not result in improved simulation accuracy.

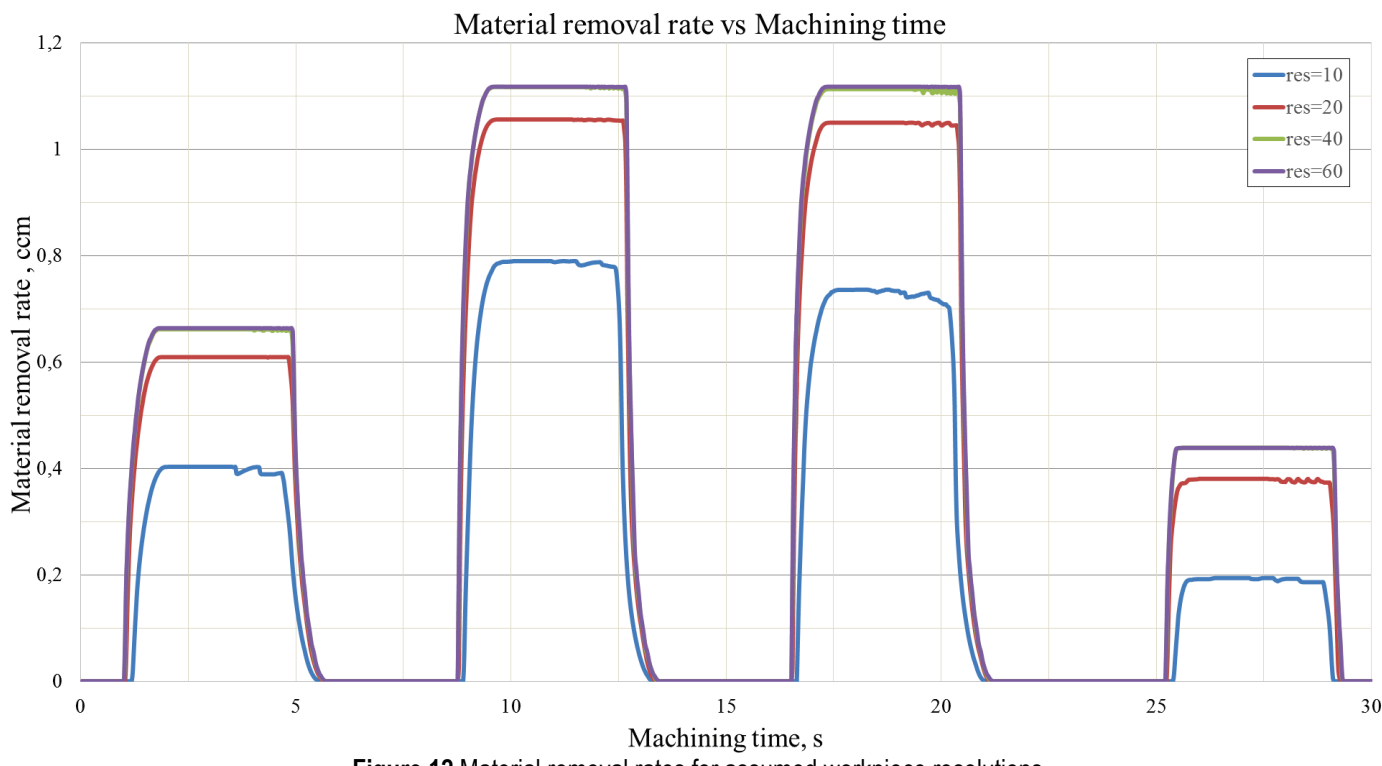

Figure 12 Material removal rates for assumed workpiece resolutions

Material removal ratios for different workpiece resolutions are shown in Fig. 12. Differences between four simulation variants are analogous to the ones obtained for tangential force value. Therefore, it can be inferred that material removal ratio is one of the factors affecting values of simulated cutting forces.

\section{CONCLUSION}

Based on the analysis of obtained simulation results, the following conclusions were drawn:

1) Use of workpiece resolution value that is lower than recommended (res $1=10)$ results in severe underestimations in both cutting force and material removal rate values;

2) Interestingly, underestimation of workpiece resolution results in lower values of material removal rate and cutting force, which is contrary to the information provided by the software developer;

3) Results for workpiece resolution res $2=20$ calculated with the use of Eq. (1) are underestimated by $6-8 \%$ in comparison to ones obtained with the use of higher resolutions; therefore, further increasing workpiece resolution and analysis of obtained results is recommended;

4) In the analysed case, best results were obtained with resolution value twice as high as proposed by the software developer $($ res $3=40)$;

5) Increasing workpiece resolution above a certain value does not yield a visible improvement in simulation results (as seen for res $3=40$ vs res $4=60$ ), resulting only in longer computation times and slower operation of $3 \mathrm{D}$ cutting process visualization module- this can be especially problematic for complex workpiece geometries.

\section{REFERENCES}

[1] Zhang, P. \& Liu, Z. (2017). Plastic deformation and critical condition for orthogonal machining two-layered materials with laser cladded Cr-Ni-based stainless steel onto AISI 1045. Journal of Cleaner Production, 149, 1033-1044. https://doi.org/10.1016/j.jclepro.2017.02.167

[2] Grossi, N., Sallese, L., Scippa, A., \& Campatelli, G. (2017). Improved experimental-analytical approach to compute speed-varying tool-tip. Precision Engineering, 48, 114-122. https://doi.org/10.1016/j.precisioneng.2016.11.011

[3] Krolczyk, G., Legutko, S., \& Raos, P. (2013). Cutting wedge wear examination during turning of duplex stainless steel. Tehnički vjesnik, 20(3), 413-418.

[4] Nieslony, P., Cichosz, P., Krolczyk, G. M., Legutko, S., Smyczek, D., \& Kolodziej, M. (2016). Experimental studies of the cutting force and surface morphology of explosively clad Ti - steel plates. Measurement, 78, 129-137. https://doi.org/10.1016/j.measurement.2015.10.005

[5] Maruda, R. W., Krolczyk, G. M., Nieslony, P., Wojciechowski, S., Michalski, M., \& Legutko, S. (2016). The influence of the cooling conditions on the cutting tool wear and the chip formation mechanism. Journal of Manufacturing Processes, 24(1), 107-115. https://doi.org/10.1016/j.jmapro.2016.08.006

[6] Krolczyk, G., Legutko, S., \& Stoić, A. (2013). Influence of cutting parameters and conditions onto surface hardness of duplex stainless steel after turning process. Tehnički vjesnik, 20(6), 1077-1080.

[7] Maruda, R. W., Krolczyk, G. M., Feldshtein, E., Nieslony, P., Tyliszczak, B., Pusavec, F. (2017). Tool wear characterizations in finish turning of AISI 1045 carbon steel for MQCL conditions. Wear, 372-373, 54-67. https://doi.org/10.1016/j.wear.2016.12.006 
[8] Wojciechowski, S., Maruda, R. W., Nieslony, P., Krolczyk, G. M. (2016). Investigation on the edge forces in ball end milling of hardened steel. International Journal of Mechanical Sciences, 119, 360-369.

https://doi.org/10.1016/j.jmecsci.2016.10.034

[9] Krolczyk, G. M., Nieslony, P., Maruda, R. W., \& Wojciechowski, S. (2017). Dry cutting effect in turning of a duplex stainless steel as a key factor in Clean Production. Journal of Cleaner Production, 142, 3343-3354. https://doi.org/10.1016/j.jclepro.2016.10.136

[10] Niesłony, P., Jarosz, K., \& Löschner, P. (2016). Porównanie strategii frezowania czołowego w celu wyboru optymalnego sposobu obróbki. STAL Metale \& Nowe Technologie, 10-11, 45-48.

[11] Jarosz, K., Löschner, P., \& Królczyk, G. (2016). Weryfikacja i optymalizacja programów sterujących na frezarki $\mathrm{CNC}$ metodą elementów skończonych w środowisku programu TWS Production Module 3D. Mechanik, 10, 1458-1459. https://doi.org/10.17814/mechanik.2016.10.409

[12] Jarosz K., Löschner P., Niesłony P., \& Królczyk G. (2017). Optimization of CNC Face Milling Process of AL-6061-T6 Aluminum Alloy. Journal of Machine Engineering, 17(1). 69-77.

[13] Third Wave System Production Module 3D User's Manual.

[14] Third Wave System Tech Nodes. A Third Wave Systems Technical Newsletter - Workpiece Resolution, 4/2015.

\section{Authors' addresses}

Piotr NIESŁONY, DSc, Deng, Professor at the Opole University of Technology, Opole University of Technology, Faculty of Mechanical Engineering,

Mikołajczyka 5 st., 45-271 Opole, Poland

p.nieslony@po.opole.pl

Krzysztof JAROSZ, MscEng, PhD Student at the Opole University of Technology, Opole University of Technology, Faculty of Mechanical Engineering,

Mikołajczyka 5 st., 45-271 Opole, Poland

jarosz.krzysztof91@gmail.com

Piotr LÖSCHNER, MscEng, PhD Student at the Opole University of Technology Opole University of Technology, Faculty of Mechanical Engineering,

Mikołajczyka 5 st., 45-271 Opole, Poland

pleszner1@gmail.com 